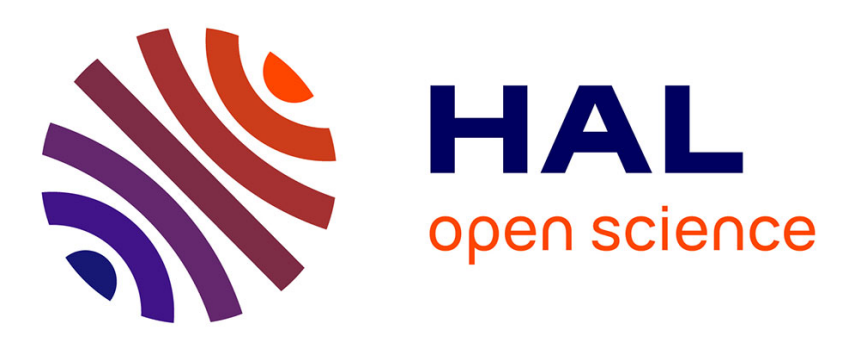

\title{
Extensive validation and possible improvements of the FSC method
}

\author{
Antoine Leconte, Philippe Papillon
}

\section{To cite this version:}

Antoine Leconte, Philippe Papillon. Extensive validation and possible improvements of the FSC method. EuroSun 2014 - 2014 International Conference on Solar Energy and Buildings, International Solar Energy Society, Sep 2014, Aix-les-Bains, France. 10.18086/eurosun.2014.03.14 cea-02948530

\section{HAL Id: cea-02948530 https://hal-cea.archives-ouvertes.fr/cea-02948530}

Submitted on 24 Sep 2020

HAL is a multi-disciplinary open access archive for the deposit and dissemination of scientific research documents, whether they are published or not. The documents may come from teaching and research institutions in France or abroad, or from public or private research centers.
L'archive ouverte pluridisciplinaire HAL, est destinée au dépôt et à la diffusion de documents scientifiques de niveau recherche, publiés ou non, émanant des établissements d'enseignement et de recherche français ou étrangers, des laboratoires publics ou privés. 


\title{
Extensive validation and possible improvements of the FSC method
}

\author{
Antoine Leconte ${ }^{1}$ and Philippe Papillon ${ }^{1}$ \\ 1 Univ. Grenoble Alpes, INES, F-73375 Le Bourget du Lac, France \\ CEA, LITEN, Department of Solar Technologies, F-73375 Le Bourget du Lac, France
}

\begin{abstract}
The FSC method is a method that characterizes solar combisystems performances thanks to a dimensionless quantity that represents the operation conditions (climate, loads and collectors features). So far, this method has been validated with a certain extent of boundary conditions and controller settings. This paper explores the limits of the current FSC method with thousands additional simulations. It further validates the FSC approach, highlights some problematic range of conditions for the accuracy of the method and suggests some improvements to reduce errors in performance estimations.
\end{abstract}

Key-words: Solar Combisystems, Characterization, Performance estimation

\section{Introduction}

Solar combisystems (SCS) are complex systems which use solar heat with an auxiliary heating system to provide energy for Space Heating (SH) and Domestic Hot Water (DHW) needs. A reliable characterization of their performances would be very helpful for users and manufacturers but such a characterization is very complicated because SCS performances can vary a lot according to system design and operation (hydraulic schemes, control strategies, collectors' area, storage volume...), SH and DHW needs, solar resources.

Letz et al. (2009) has introduced a new dimensionless quantity called the Fractional Solar Consumption (FSC) which takes into account the climate, the heating loads, the collector size and orientation. This number is completely independent from the studied SCS. The author showed that fractional energy savings (FSAV) of each SCS can be expressed as a quadratic function of FSC. The curve obtained this way for a SCS is therefore the characterization of its performances.

Although the simulations made for this study take into account different boundary conditions ( 3 kinds of building, 3 kinds of climates, several collectors area...), further work is still required to explore the extents and limits of the methodology. The sensibility of the FSC method with respect to some other operation parameters (position and efficiency of the collectors, DHW draw offs, temperature set points, heating loop sizing...) needs to be investigated. The goal of this work is to further validate the FSC method thanks to numerous simulations and to propose some possible improvements.

\section{The data base}

One SCS, with a storage tank of about 750L, has been tested several times in a row on a semi-virtual test bench according to the SCSPT method. (Albaric, 2008). It has been tested under several working conditions (climate, building, collector size, controller tuning). Thus, a complete detailed model could be developed and validated within the TRNSYS software. 


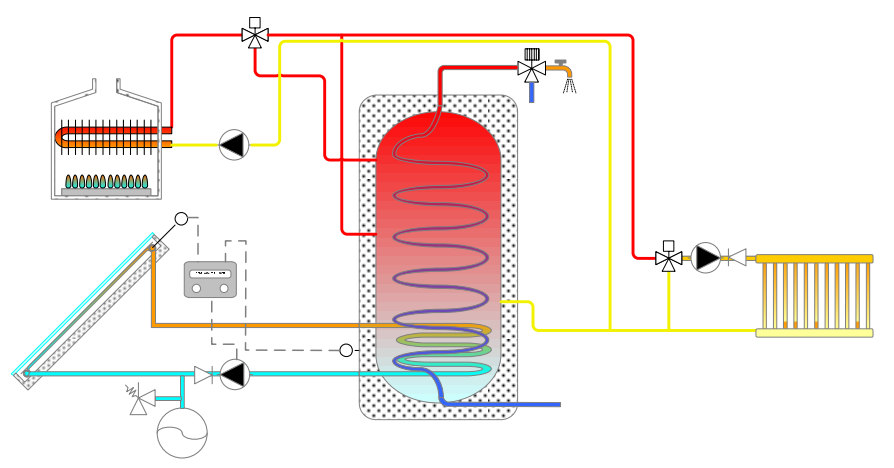

Fig. 1: Scheme of the Solar Combisystem tested, modelled and validated

This validated model has been used to calculate weekly, monthly and annual data of the SCS operations for thousands different working environments, varying: building types, climates, collector areas, collector azimuths, collector slopes, collector performances, DHW profiles, room temperature set points, space heating loop sizing,... The different variations of simulation conditions are summed up in Tab. 1 and described below. Underlined values represent what is called "classical" simulation conditions in the next paragraphs.

Tab. 1: Overview of the different simulation conditions considered in this paper

\begin{tabular}{|c|c|}
\hline Building Type & 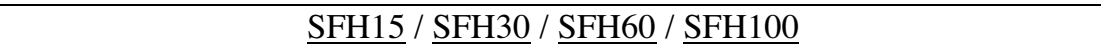 \\
\hline Climate & 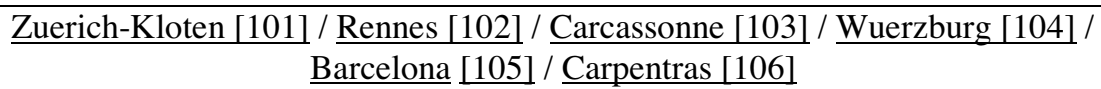 \\
\hline Collectors Area & ${\underline{7 m^{2}}}^{2} 10 \mathrm{~m}^{2} / 13 \mathrm{~m}^{2} / 16 \mathrm{~m}^{2} / \underline{19 m}^{2} / 22 \mathrm{~m}^{2}$ \\
\hline Collectors Type & Type0 / Type 1 \\
\hline Collectors Slope & $\underline{45}^{\circ} / 22^{\circ} / 68^{\circ}$ \\
\hline Collectors Azimuth & $\underline{0}^{\circ} / 45^{\circ} /-45^{\circ}$ \\
\hline Draw Offs Profile & $100 / \underline{200} / 400 / 111 / 222$ \\
\hline SH Loop Sizing & $\underline{1} / 0.75 / 1.25$ \\
\hline TroomSetPoint & 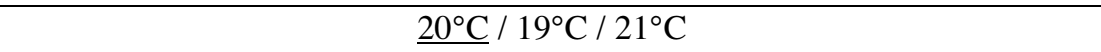 \\
\hline
\end{tabular}

- Building type

The different kinds of building considered are Single Family Houses (SFH) as defined in IEA SHC Task32 (Heimrath et Haller, 2007). The associated number represents the yearly SH needs in $\mathrm{kWh} . \mathrm{m}^{-2}$ for the Zurich climate.

- Climates

The weather data used in those simulations are taken from the Typical Meteorological Year files (TMY2 files) corresponding to the climates indicated in Tab. 1.

- Collectors layout

In order to check the influence of collectors' layout on SCS performances, several parameters are considered: area, slope $\left(0^{\circ}\right.$ is horizontal $)$, azimuth $\left(0^{\circ}\right.$ is facing the equator, $90^{\circ}$ is facing east) and thermal performances as described in Tab.2. The tested system's controller modifies the collector loop flowrate in order to keep a temperature difference of about $10^{\circ} \mathrm{K}$ between the storage tank and the collectors. This feature is taken into account within the simulations, so the flowrate is self-adjusted according to the collectors' size. 
Tab. 2: Parameters of the two kinds of collectors considered in the simulations

\begin{tabular}{|c|c|c|c|c|c|c|}
\hline $\begin{array}{c}\text { Collectors } \\
\text { Type }\end{array}$ & $\begin{array}{c}\text { n0 } \\
\text { Normal } \\
\text { incidence } \\
\text { efficiency } \\
{[-]}\end{array}$ & $\begin{array}{c}\text { a1 } \\
\text { Linear heat } \\
\text { loss } \\
\text { coefficient } \\
{\left[\mathrm{W} \cdot \mathrm{m}^{-2} \cdot \mathrm{K}^{-1}\right]}\end{array}$ & $\begin{array}{c}\text { a2 } \\
\text { Linear heat } \\
\text { loss } \\
\text { coefficient } \\
{\left[\mathrm{W} \cdot \mathrm{m}^{-2} \cdot \mathrm{K}^{-2}\right]}\end{array}$ & 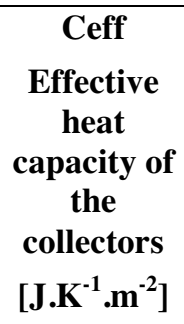 & $\begin{array}{c}\text { Kdiff } \\
\text { Incidence } \\
\text { angle } \\
\text { modifier for } \\
\text { diffuse } \\
\text { radiation } \\
{[-]}\end{array}$ & $\begin{array}{c}\text { b0 } \\
\text { Angle dependence } \\
\text { of the } \\
\text { transmittance } \\
\text { absorptance } \\
\text { product } \\
{[-]}\end{array}$ \\
\hline 0 & 0.80 & 3.50 & 0.015 & 7000 & 0.90 & 0.18 \\
\hline 1 & 0.75 & 5.46 & 0.021 & 7000 & 0.88 & 0.18 \\
\hline
\end{tabular}

- Draw-Offs profile

In order to check the influence of different kinds of DHW needs, the draw-offs profile presented in Tab. 3 are considered for the simulations. All load profiles are based on a 6 minute timestep.

Tab. 3: Characteristics of the draw-offs profiles considered in simulations

\begin{tabular}{|c|c|c|}
\hline$\#$ & $\begin{array}{c}\text { Daily volume of hot water at } \mathbf{4 5}^{\circ} \mathbf{C} \\
\text { withdrawn }\end{array}$ & Description \\
\hline $\mathbf{1 0 0}$ & $100 \mathrm{~L} /$ day & Annual profile generated with the program from (Jordan and \\
Vajen, 2001)
\end{tabular}

- Space Heating loop

The Space Heating ( $\mathrm{SH}$ ) loop is composed of thermostatic valve feeding radiators at a temperature calculated by the system controller. The radiator nominal power depends on the working environment of the system (climate and building). Those preset values are increased $(+25 \%)$ or decreased $(-25 \%)$ to check the influence of SH loop sizing on the system performances.

The considered controller, specific to the modelled system, calculates a temperature set point for the space heating loop according to the ambient temperature, the room temperature and the kind of building. For information, Tab. 4 below illustrates the maximum weekly average temperature in the different configurations.

Tab. 4: Maximum weekly average value of the heat loop temperature (in ${ }^{\circ} \mathrm{C}$ ) depending on buildings (lines) and climates (columns)

\begin{tabular}{|c|c|c|c|c|c|c|}
\hline & Zuerich & Rennes & Carcassonne & Wuerzburg & Barcelona & Carpentras \\
\hline SFH15 & 28 & 26 & 25 & 29 & 25 & 24 \\
\hline SFH 30 & 29 & 28 & 27 & 30 & 26 & 27 \\
\hline SFH 60 & 33 & 32 & 31 & 34 & 28 & 31 \\
\hline SFH 100 & 49 & 44 & 42 & 50 & 37 & 42 \\
\hline
\end{tabular}

- Room temperature set point

The room set point temperature (TroomSetPoint) is defined as $19^{\circ} \mathrm{C}, 20^{\circ} \mathrm{C}$ or $21^{\circ} \mathrm{C}$ depending on the simulation.

The complete combination of all these conditions would lead to 233280 annual simulations. Only the most relevant ones are really carried out, offering almost 2500 monthly and weekly information about energy and system operation.

\section{Results with the current method}

The current FSC method has been applied to all simulations results according to methodology presented by 
(Letz, 2009).

Firstly, monthly reference energy is calculated according to (eq. 1). It represents the amount of energy that would be consumed by a classic thermal system, without any active solar inputs, to meet the same $\mathrm{SH}$ and DHW needs $\left(Q_{S H, n d}\right.$ and $Q_{D H W, n d}$ respectively). It is assumed here that the annual efficiency of the reference system $\left(\eta_{A u x, r e f}\right)$ is $85 \%$ and that the annual heat losses of its store $\left(Q_{\text {Loss,ref }}\right)$ are $644 \mathrm{kWh}$.

$Q_{\text {Ref,th }}=\frac{Q_{S H, n d}+Q_{D H W, n d}+Q_{\text {Loss,ref }}}{\eta_{A u x, r e f}}$ (eq. 1)

The monthly reference energy is compared to the monthly solar irradiation at the collectors surface $\left(S_{\text {Coll }} \cdot Q_{\text {Sol }}\right.$ with $S_{\text {Coll }}$ the collectors area) in order to calculate the usable solar energy (eq. 2).

$Q_{\text {Solar,Usable }}=\sum_{i=\text { month }} \min \left(S_{\text {Coll }} \cdot Q_{\text {Sol }}(i) ; Q_{\text {Ref,th }}(i)\right) \quad$ (eq. 2)

The Fractional Solar Consumption is finally calculated as the ratio between the usable solar energy and the global reference energy (eq. 3). Thus, the FSC characterizes a given working environment from energy needs $\left(Q_{S H, n d}\right.$ and $\left.Q_{D H W, n d}\right)$ and the solar resource $\left(S_{\text {Coll }} \cdot Q_{S o l}\right)$

$F S C=\frac{Q_{\text {Solar }, \text { ssable }}}{Q_{\text {Ref,th }}} \quad$ (eq. 3)

Each $F S C$ calculated is linked to the energy savings (eq. 4) of the system in the corresponding working environment, giving a point $\left(F S C, F S A V_{t h}\right)$.

$F S A V_{t h}=1-\frac{Q_{A u x, i n}}{Q_{R e f, t h}} \quad$ (eq. 4$)$

When representing all the points calculated from "classical" simulation conditions (Fig. 2), the system performances can be represented with a second-order polynomial (eq. 5), as expected by the current FSC method. Dashed lines on the figures of this paper represent the range of systems simulated in the framework of IEA SHC Task26 (Weiss, 2003). For each Figure presented in this paper, the FSC curve is identified from the represented points. Thus a new curve is identified in each Figure, according to the simulation conditions and the hypothesis that are studied.

$F S A V_{t h, G R S}=a+b . F S C+c . F S C^{2}$
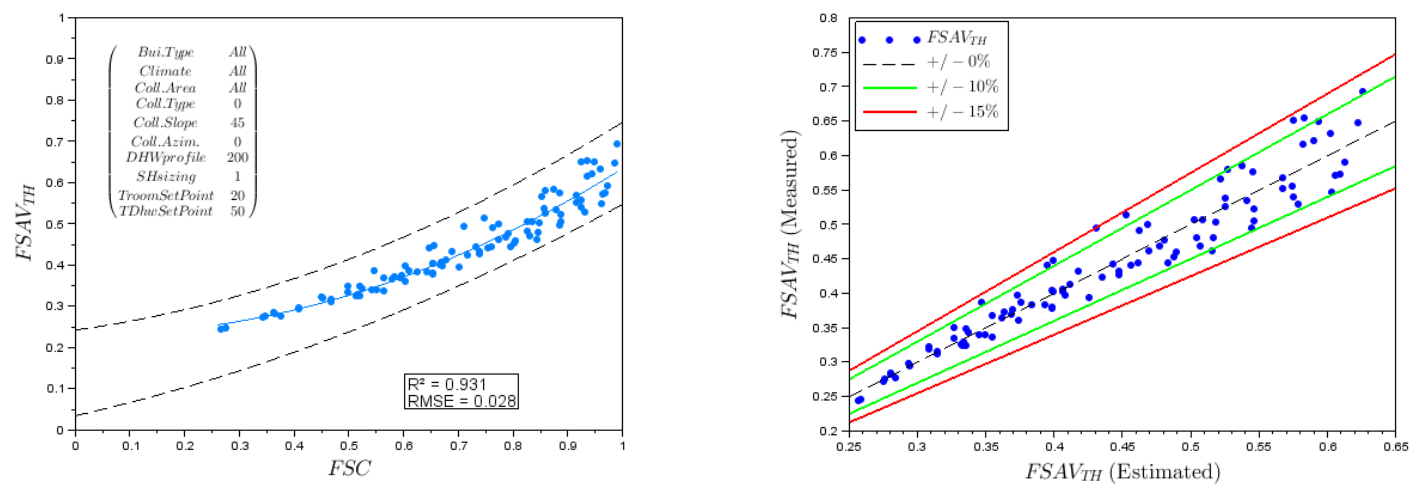

Fig. 2: FSAV-FSC curve calculated with "classical" simulation conditions results (left) and differences between measured performances and estimated performances (right)

Letz et al. (2009) have developed the FSC methodology with simulations of several systems mostly in different climates, buildings and collectors areas. The authors suggest further investigations to check the limits for the method. They have especially noticed that the hot water load has a significant impact on the accuracy of the method. This paper aims to test the methodology using the different conditions described in the previous paragraph (Tab. 1). Considering all the available simulations leads to widely scattered dots on the $\left[F S C, F S A V_{t h}\right]$ plan (Fig. 3). 

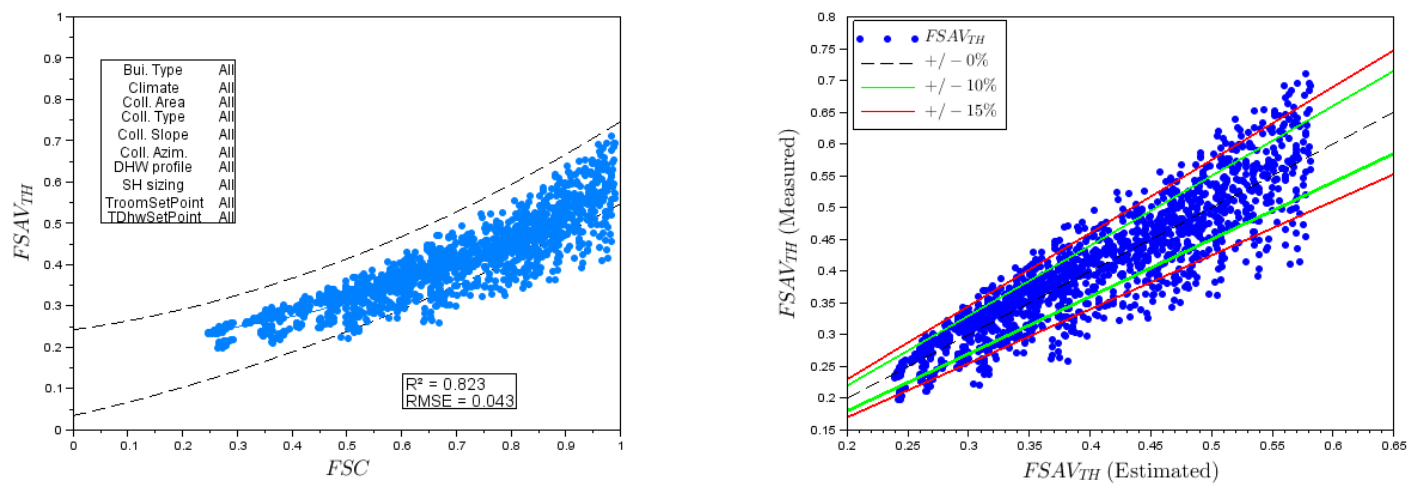

Fig. 3: FSAV-FSC curve calculated with all results available (left) and differences between measured performances and estimated performances (right)

Firstly, one can observe that even for the "classical" simulations conditions (Fig. 2), there is a scattering of points that is larger and larger when FSC get close to 1. When looking at the points distinguishing the climates, it seems that for a given FSC value, sunny climates are more favorable for SCS performances.

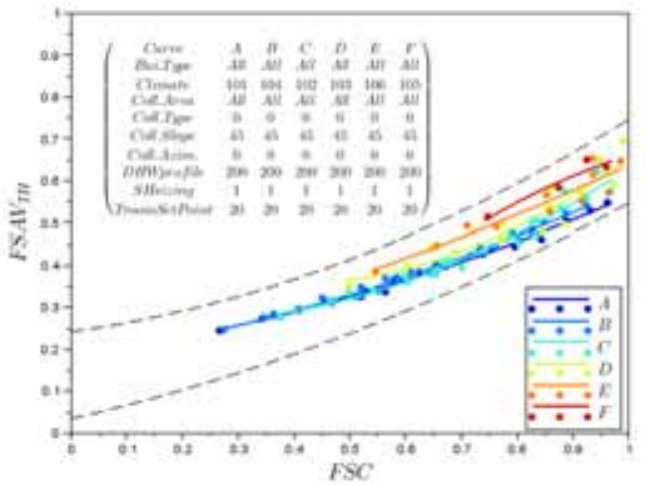

Fig. 4: FSAV-FSC curve calculated with "classical" simulation conditions results

As expected by Letz et. al (2009), both amount and distribution of DHW loads have significant effect on FSC curve identification (left plot on Fig. 5). The higher the FSC, the larger the differences between curves.

Some investigation about how to reduce the scattering of points introduced by DHW load profile and sunny climates would be helpful for SCS characterization. The current FSC method characterizes the SCS including the quality of its collectors (right plot on Fig. 5). It could be also interesting to characterize the system independently from the collectors' performances so the curve could be used for the studied system working with any kind of collectors.
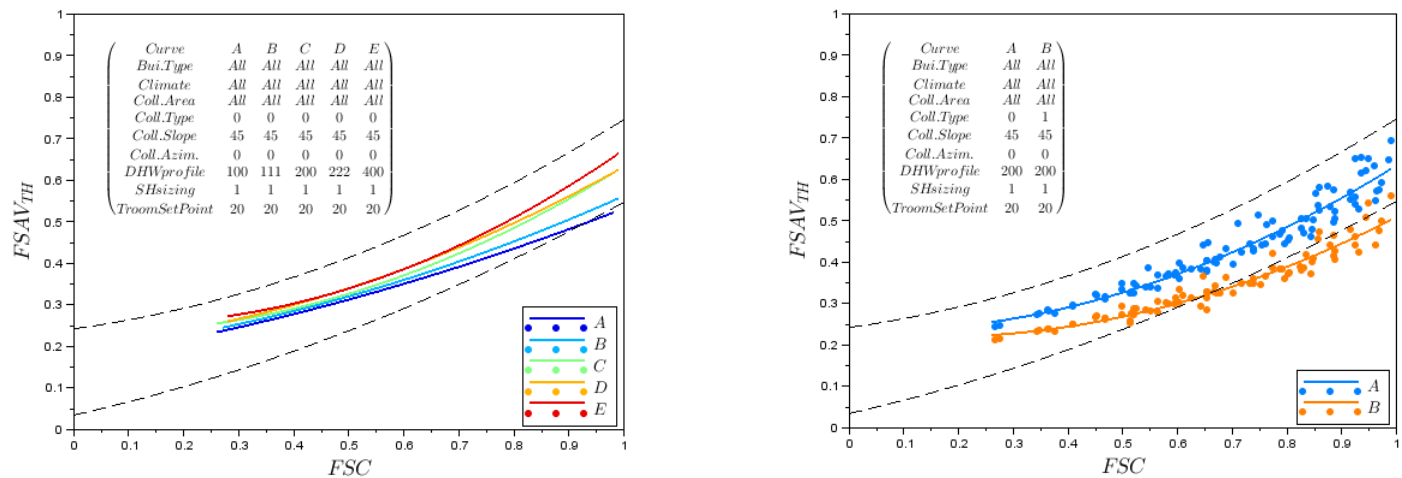

Fig. 5: FSAV-FSC curve calculated with different DHW load profiles (left) and with different collectors efficiencies (right)

On the other hand, among the different conditions from (Tab. 1), some of them seem to have very little 
influence on the estimated curve:

- The variation of SH loop sizing considered in (Tab. 1) has little effect in this case on the system performances, without changing FSC at all. Identified curves are then similar (Fig. 6).

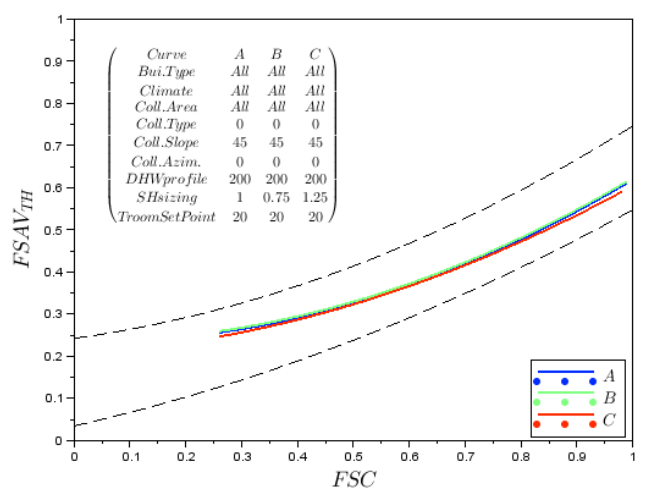

Fig. 6: FSAV-FSC curve calculated with different SH loop sizing

- Slope and azimuth of collectors change the solar energy usable and then FSC. But the change in energy savings in those cases is consistent with the FSC curves (Fig. 7). The methodology seems suitable to characterize a SCS whatever the orientation of the collectors.

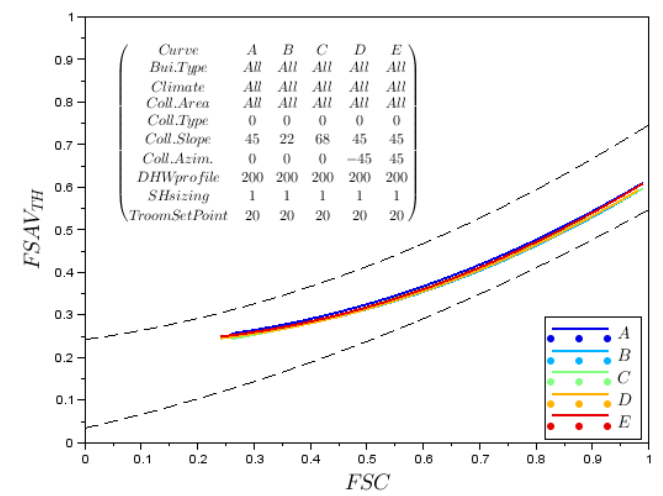

Fig. 7: FSAV-FSC curve calculated with different collectors orientations

- The energy needed for SH and the way this energy is prepared depend on the room set point temperature. Thus, TroomSetPoint has an influence on both FSC and $F S A V_{t h}$ but the identified curves are similar whatever the set point is (Fig. 8).

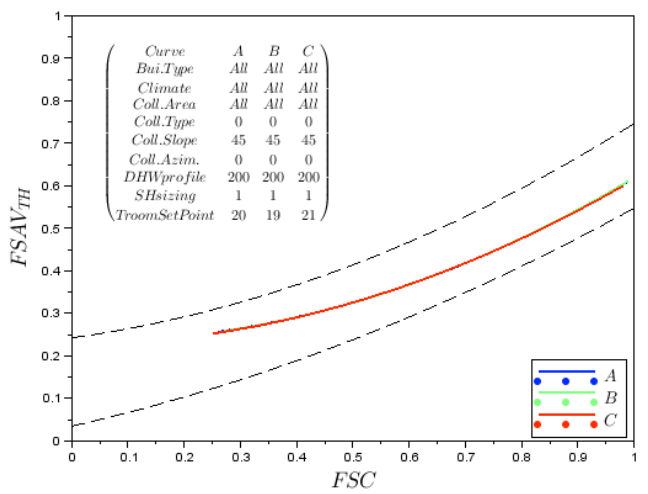

Fig. 8: FSAV-FSC curve calculated with different room temperature set points

\section{Improvement of the FSC method}

Two ways to eventually improve the FSC method are explored hereunder: 
- Integration of collectors' performances in the FSC calculations

Currently, a FSC curve characterizes a combisystem including the kind of collector it is working with. To characterize the same SCS with other collectors that can be more or less efficient, other data are needed to identify the corresponding curve. Thus, a very large amount of data is needed if one wants to characterize a SCS with every possible kind of collector. Moreover, the comparison of performances between different systems depends on the collector used by each system. This introduces a kind of bias: the current FSC curve doesn't represent the system performances intrinsically. So, it would be interesting if the FSC curve is independent of the collectors' performances.

So far, the FSC calculations are based on $Q_{S o l}$, the solar radiations at the collectors' surface to calculate the maximum solar energy that can be collected over the year. However, the collectors' performances actually reduce intrinsically this maximum collector energy $Q_{C O L L, M a x}$. Thus the solar energy can be refined considering this phenomenon (eq. 6).

$Q_{\text {Solar,Usable,2 }}=\sum_{i=\text { month }} \min \left(\operatorname{Surf}_{\text {Coll }} \cdot Q_{\text {COLL,Max }}(i) ; Q_{\text {Ref,th }}(i)\right) \quad$ (eq. 6)

In this study, the maximum energy that can be collected is calculated by integrating the power $\dot{Q}_{C O L L, M a x}$ as defined in (eq. 7), which involves the main collectors' performance parameters $\left(\eta_{0}, a_{1}\right.$ and $\left.a_{2}\right)$ and climatic information $\left(\dot{Q}_{S o l}\right.$ and $\left.T_{a m b}\right)$ at each timestep of the simulation (3min timestep). Only positive values are integrated (it is the meaning of the + sign in (eq. 7)) .

$\dot{Q}_{C O L L, M a x}=\left[\eta_{0} \dot{Q}_{S o l}-a_{1}\left(T_{C O L L, r e f}-T_{a m b}\right)-a_{2}\left(T_{C O L L, r e f}-T_{a m b}\right)^{2}\right]^{+}$

The power $\dot{Q}_{C O L L, M a x}$ also needs a reference temperature $T_{C O L L, r e f}$ to estimate the heat losses of the collectors. In this study, this temperature is taken as the average between $T_{D H W, r e f}$ the reference temperature of DHW needs and $T_{S H, r e f}$ the reference temperature of $\mathrm{SH}$ needs.

$T_{\text {COLL }, \text { ref }}=\frac{T_{S H, r e f}+T_{D H W, r e f}}{2} \quad$ (eq. 8$)$

$T_{D H W, r e f}$ is taken as the set point temperature of the final DHW ( $45^{\circ} \mathrm{C}$ in those calculations) and $T_{S H, r e f}$ is calculated according to $\dot{Q}_{S H, n e e d}$ the heat needed in the building to keep the room at its set point temperature $\left(20^{\circ} \mathrm{C}\right.$ in those calculations) and characteristics of the heat emitters $\left(K_{e m}\right.$ and the exponent $\left.n_{e m}\right)$.

$T_{D H W, \text { ref }}=T_{D H W, \text { setPoint }}($ eq. 9)

$T_{S H, \text { ref }}=T_{\text {room,setPoint }}+\left(\frac{\dot{Q}_{S H, \text { need }}}{K_{\text {em }}}\right)^{\frac{1}{n_{e m}}} \quad$ (eq. 10)

Finally, with this definition of $Q_{C O L L, M a x}$, each environment is still characterized by the climate, the building, the collectors' area but also by the collectors' thermal performances and the heat emitter type. For each one of

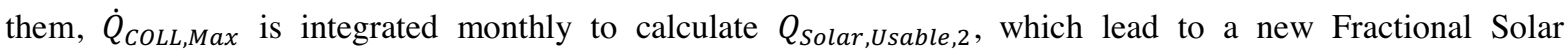
Consumption $\mathrm{FSC}_{2}$ when combined with (eq. 3).

The use of $F S C_{2}$ instead of $F S C$ seems to improve the methodology as shown by Fig. 9.
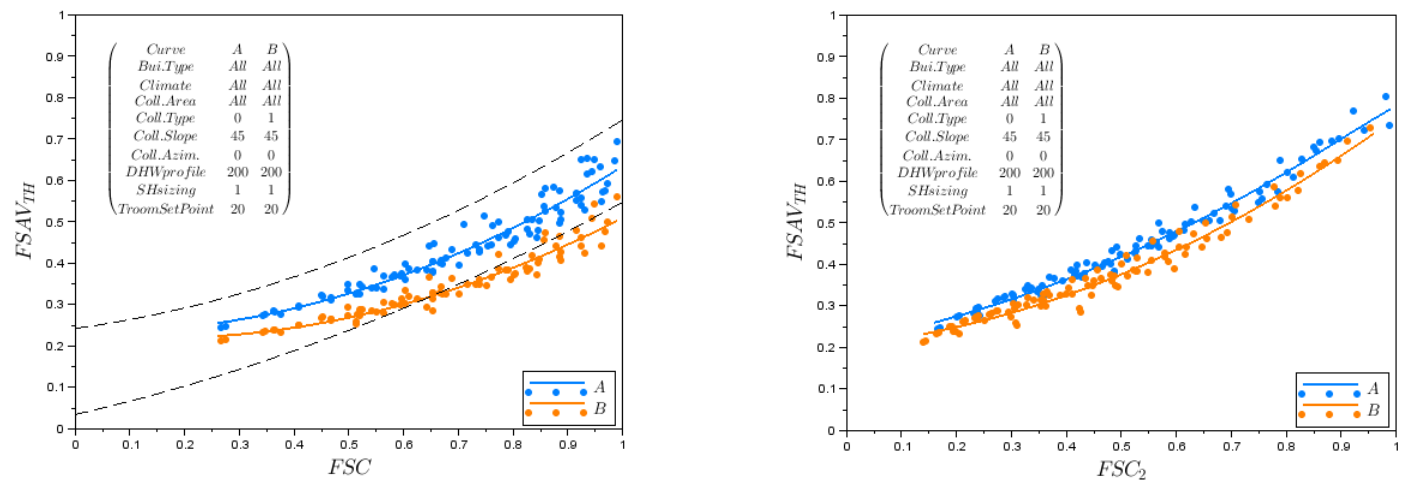

Fig. 9: FSAV-FSC curve calculated with different collectors efficiencies (left: with classical FSC, right: with new FSC2) 
Dashed lines are not represented anymore on graphs involving $F S C_{2}$ because the performances of systems evaluated in the framework of Task26 are not studied with $F S C_{2}$. One can see on (Fig. 10) that the use of $F S C_{2}$ brings closer the characteristic curves of the SCS with two different collector type. There is still some difference between them (in the range of 0.05 points in absolute in this case) but this result shows that the use of collectors' parameters in the definition of the fractional solar consumption is relevant. Some future improvements can still be searched like the definition of $T_{C O L L, \text { ref }}$ for instance.

The new criterion $F S C_{2}$ also has positive influence on the other critical aspects mentioned in the paragraph 3 :

- The influence of climate is reduced on the identified curves (Fig. 10)
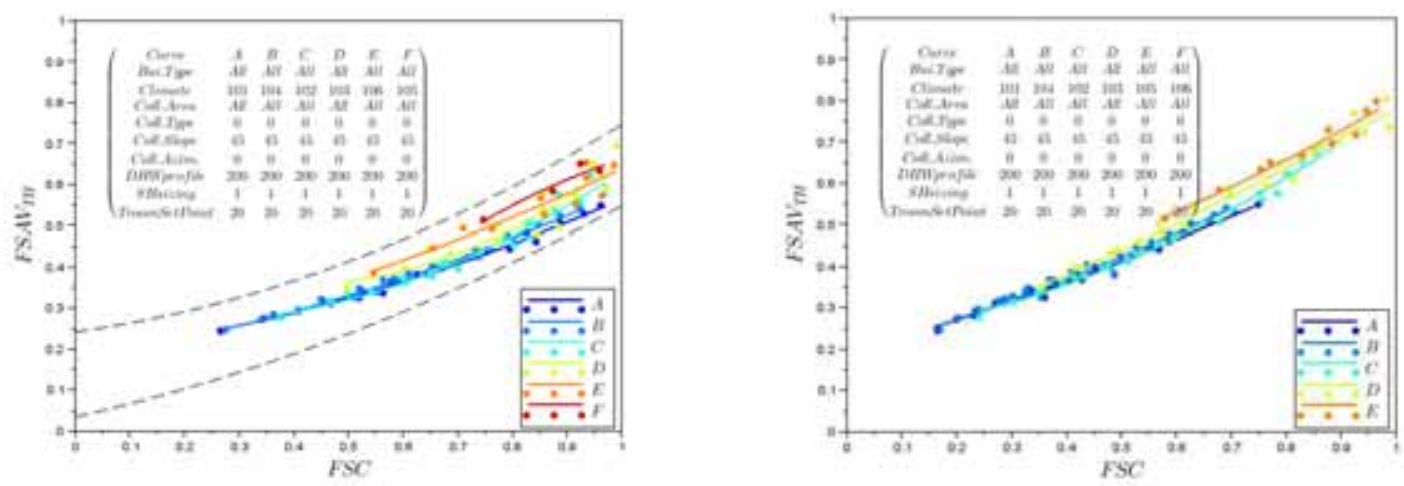

Fig. 10: FSAV-FSC curve calculated with "classical" simulation conditions results (left: with classical FSC, right: with new FSC2)

- The influence of DHW loads is reduced on the identified curves (Fig. 11)
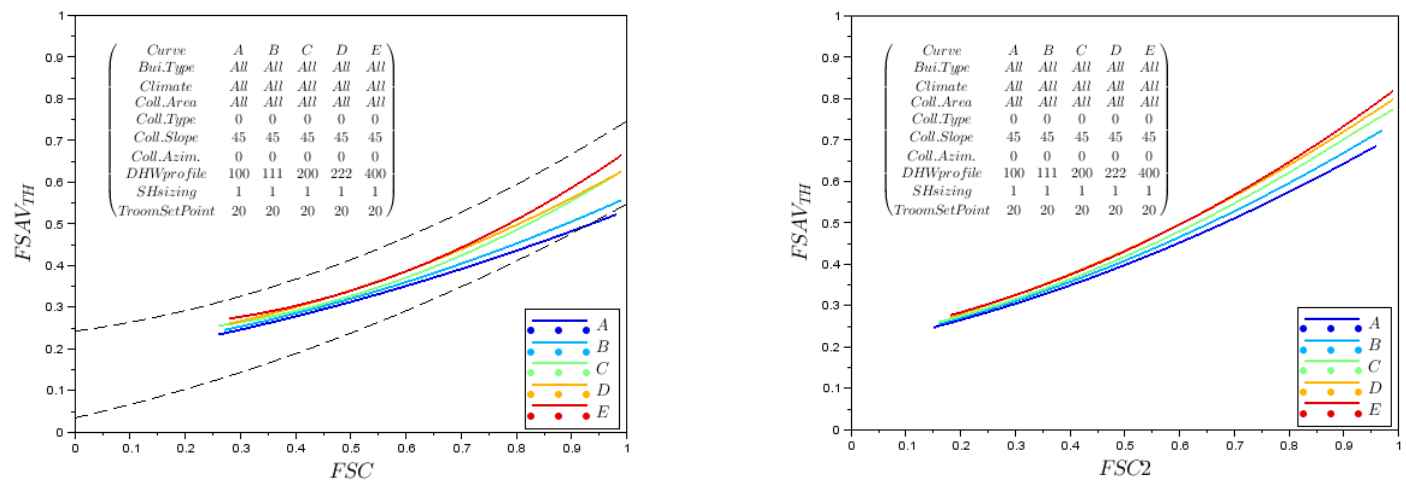

Fig. 11: FSAV-FSC curves calculated with different DHW load profiles (left: with classical FSC, right: with new FSC2)

As shown by Fig. 12 compared with Fig. 3, when considering all available simulations results, points plotted according to $\left[F S C_{2}, F S A V_{t h}\right]$ are really less scattered than the $\left[F S C, F S A V_{t h}\right]$ case. Nearly all of the performance estimations are within the $\pm 15 \%$ precision. This leads from a low correlation coefficient $\left(\mathrm{R}^{2}=0.823\right)$ to an almost acceptable one $\left(\mathrm{R}^{2}=0.967\right)$. 

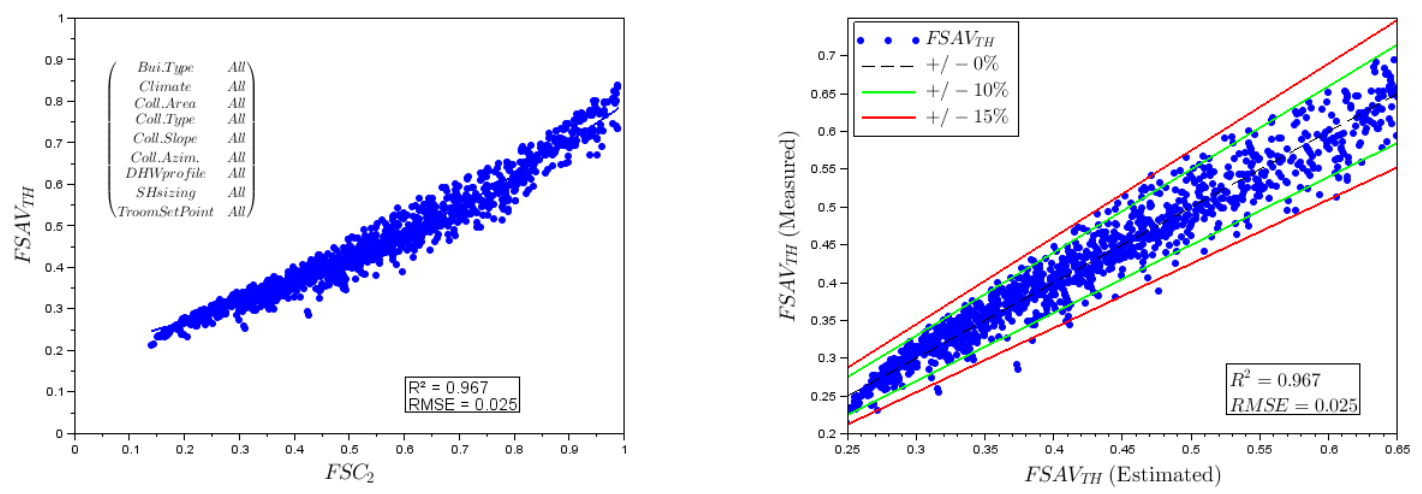

Fig. 12: FSAV-FSC curve calculated with all results available (left) and differences between measured performances and estimated performances (right)

- Further reduction of the scattering of points

The current FSC method is based on global amount of energy. However it seems that the FSC curve is also sensitive to other aspects of the energy supply and energy demand. For instance, for a given FSC, the system doesn't reach exactly the same performance whether it is working in a sunny climate or not. The approach envisaged here is based on an entropy-like number. The number $\dot{S}_{C O L L}$ expressed in (eq. 11) is calculated at each timestep and integrated in order to have a global $S_{C O L L}$ for each working environment.

$\dot{S}_{C O L L}=\frac{\dot{Q}_{C O L L, M a x}}{T_{\text {COLL, } \text { ref }}}($ eq. 11)

$S_{C O L L}$ is combined to $F S C_{2}$ like in (eq. 12) to intend to attempting to interpolate the performance $F S A V_{t h}$ as a 2D surface.

$F S A V_{t h, G R S}=a+b \cdot F S C_{2}+c \cdot S_{C O L L}+d \cdot F S C_{2} \cdot S_{C O L L}+e \cdot F S C_{2}{ }^{2}+f \cdot S_{C O L L}{ }^{2} \quad$ (eq. 12)

Considering all available simulation results, (Fig. 13) shows that the use of $S_{C O L L}$ as suggested above brings further precision to the methodology. Nearly all of the performance estimations are then within the $\pm 10 \%$ precision. The correlation coefficient is also a bit higher $\left(\mathrm{R}^{2}=0.979\right)$.
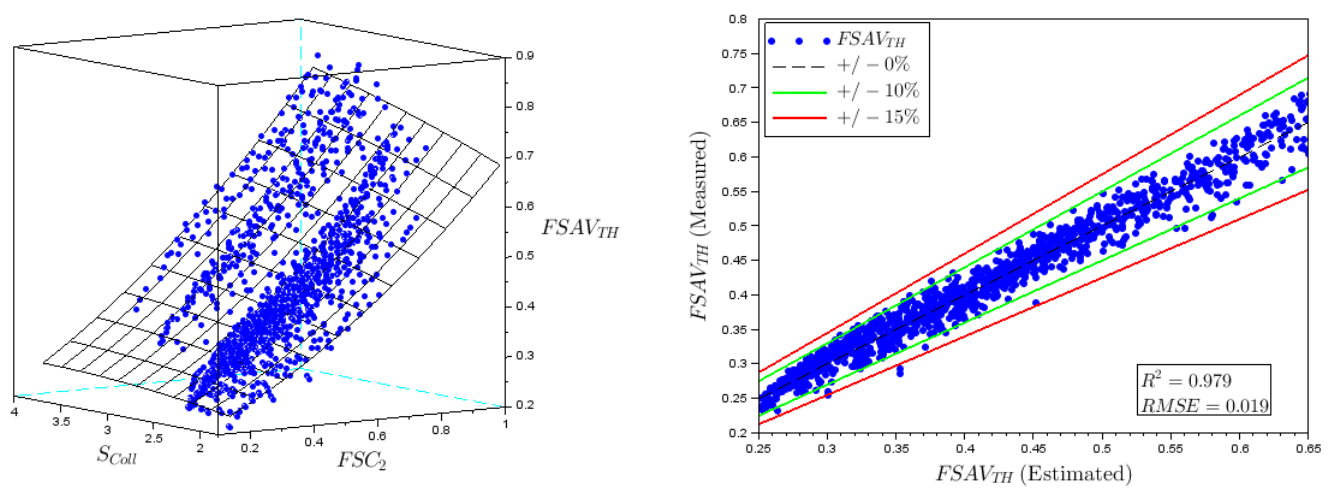

Fig. 13: FSAV-FSC curve calculated with all results available (left) and differences between measured performances and estimated performances (right)

\section{Conclusions}

A validated detailed model of a Solar Combisystem is used to simulate and estimate the system thermal performances in various working conditions (weather, buildings, water draw-offs, room temperature set point,...) and different sizing options (nominal power of the heat emitter, collectors type, area, slope, orientation,...). Almost 2500 simulation results are available.

Firstly, those results are used to check the availability of the current FSC method Characteristic curves identified according to this method are studied considering different sets of simulation configurations. This 
extensive validation shows that the FSC method gives a reliable characteristic curve as long as the draw offs profile is the same for every $\left[F S C, F S A V_{t h}\right]$ points. All other parameters have little impact on the characteristic curve identification. However, some improvement would strengthen the methodology and enhance its generalization. For instance, it would be very interesting if the scattering of points could be reduced and if the characteristic curve could be identified whatever the performances of collectors.

Finally extensions of the FSC method are proposed to try to tackle the improvements suggested above:

- The use of another Fractional Solar Consumption, $F S C_{2}$, based on a maximum solar energy

"collectable" calculated from main collector performance parameters;

- The use of a second characteristic number $S_{C O L L}$ that takes into account a global reference temperature

in an entropic way, in combination with $\mathrm{FSC}_{2}$ for identifying a characteristic 2D surface.

Both extensions show good results. They improve the accuracy of the performance estimation from the characteristic curve, even including simulations with different collector types. The precision is within $\pm 10 \%$ for nearly every point when considering all simulation results.

Those tracks seem interesting and can still be improved. Up to now, new terms $Q_{C O L L, M a x}$ and $S_{C O L L}$ are derived by integration of powers at each timestep of 3-minutes timestep simulations, which is time consuming. One improvement could be to find how to derive those terms from monthly data, like using a kind of monthly utilizability of solar energy as defined by (Duffie and Beckman, 1991).

\section{Acknowledgments}

This work is supported by the French Agency for Environment and Energy Management (ADEME) in the framework of the French "Investments for the Future" program.

\section{References}

Albaric, M., Nowag, J., and Papillon, P. 2008. Thermal Performance Evaluation of Solar Combisystems Using a Global Approach. In Eurosun 2008, 1st International Congress on Heating, Cooling and Buildings. Lisbon, Portugal.

Duffie, J.A., Beckman, W.A., 1991. Solar Engineering of Thermal Processes. Wiley Interscience, New York, 919 .

Letz T. et al., 2009. A new concept for combisystems characterization: The FSC method. Solar Energy 83, 1540-1549.

Heimrath, R., Haller M., 2007. Project Report A2 of Subtask A: The reference heating system, the template solar system. A report of IEA SHC - Task 32. Retrieved August 1, 2014, from http://archive.iea-shc.org/task32/ Jordan, Ulrike, and Klaus Vajen. "Influence Of The DHW Load Profile On The Fractional Energy Savings:" Solar Energy 69 (July 2001): 197-208. doi:10.1016/S0038-092X(00)00154-7.

European Commission, DIRECTORATE-GENERAL FOR ENERGY AND TRANSPORT, DIRECTORATE D - New Energies \& Demand Management. MANDATE TO CEN AND CENELEC FOR THE ELABORATION AND ADOPTION OF MEASUREMENT STANDARDS FOR HOUSEHOLD APPLIANCES: WATER-HEATERS, HOT WATER STORAGE APPLIANCES AND WATER HEATING SYSTEMS. Brussels, 2002. Retrived August 7, 2014, from http://www.annex28.net/pdf/m324EN.doc.

Weiss, W. (Ed.), 2003. Solar Heating Systems for Houses - A Design Handbook for Solar Combisystems. James \& James, London, UK. 